\title{
Prophylactic and immune modulatory influences of Nigella sativa Linn. in broilers exposed to biological challenge
}

\author{
Essam S. Soliman ${ }^{1}$, Rania T. Hamad ${ }^{2}$ and Amira Ahmed ${ }^{3}$
}

1. Department of Animal Hygiene, Zoonosis and Animal Behavior, Faculty of Veterinary Medicine, Suez Canal University, Ismailia 41522, Egypt; 2. Department of Pathology, Faculty of Veterinary Medicine, Suez Canal University, Ismailia 41522, Egypt; 3. Department of Poultry and Rabbit Medicine, Faculty of Veterinary Medicine, Suez Canal University, Ismailia 41522, Egypt.

Corresponding author: Essam S. Soliman, e-mail: soliman.essam@vet.suez.edu.eg

Co-authors: RTH: drrania_vet2007@yahoo.com, AA: amira_abdelaziz@vet.suez.edu.eg

Received: 01-08-2017, Accepted: 14-11-2017, Published online: 12-12-2017

doi: 10.14202/vetworld.2017.1447-1455 How to cite this article: Soliman ES, Hamad RT, Ahmed A (2017) Prophylactic and immune modulatory influences of Nigella sativa Linn. in broilers exposed to biological challenge, Veterinary World, 10(12): 1447-1455.

\begin{abstract}
Background and Aim: Prophylaxis and disease prevention is an essential strategy among biorisk management in poultry farms that stimulate and maintain the birds' immunity. The aim of this study was to investigate the prophylactic, and immune-stimulant influence of Nigella sativa Linn. in broilers under biological stress.

Materials and Methods: A total of 250 1-day-old (ross) chicks were divided into 5 groups; four of which were supplemented with $1.4 \%, 2.8 \%, 4.2 \%$, and $5.6 \% N$. sativa Linn., respectively. The four supplemented groups were challenged with Escherichia coli $\mathrm{O}_{157}: \mathrm{H}_{7} 1.5 \times 10^{8}$ at a $14^{\text {th }}$ day old. A total of 1050 samples (150 serum, $150 \mathrm{swab}$, and 750 organ samples) were collected and examined.

Results: A highly significant increase $(\mathrm{p}<0.01)$ in $5.6 \%$ N. sativa Linn. supplemented group in performance traits (body weight, weight gain, and performance index), biochemical parameters (proteinogram, liver enzymes, and creatinine), immunoglobulins concentration, and immune organs' weight. Meanwile, liver showed improvement of histoarchitecture without fibrosis. Heart showed a mild pericarditis with a mild degree of hydropic degeneration. Bursa, thymus, and spleen showed lymphoid hyperplasia.
\end{abstract}

Conclusion: A concentration of 5.6\% N. sativa Linn. in broiler's feed can improve the immune response and subsequent resistance of broilers against diseases.

Keywords: Broiler, Escherichia coli, histopathology, Nigella sativa Linn., preventive.

\section{Introduction}

The world's direction in the past decades was focusing on the usage of growth promoters for improving the productive performance; therefore, antibiotics were used extensively in poultry industry as growth promoters [1]. The results of using antibiotics were magnificent in increasing the performance traits, but they contributed the development of antibiotics-resistant bacteria [2,3]. A second brand of growth promoters was developed and used; prebiotics and probiotics that contributed enhancement in the intestinal mucosa with a significant increase in performance and resistance of bird through acting as competitive exclusive for pathogenic organisms [4-6]. Although from an economic point of view, using these products on a daily basis makes their use unpractical and expensive for the producer.

Copyright: Soliman, et al. Open Access. This article is distributed under the terms of the Creative Commons Attribution 4.0 International License (http://creativecommons.org/licenses/ by/4.0/), which permits unrestricted use, distribution, and reproduction in any medium, provided you give appropriate credit to the original author(s) and the source, provide a link to the Creative Commons license, and indicate if changes were made. The Creative Commons Public Domain Dedication waiver (http:// creativecommons.org/publicdomain/zero/1.0/) applies to the data made available in this article, unless otherwise stated.
There is a great interest in developing natural alternatives for the growth promoters. Nigella sativa Linn. and its oil have been widely used for centuries in the treatment of different physiological disorders [1]. It has been considered one of the greatest forms of healing medicine available, especially in Middle East and Asia, as it was mentioned that black seed is the remedy for all diseases except death in one of the prophetic hadith. It is also recommended for use on regular basis in Tibb-e-Nabwi (prophetic medicine) [7]. The nutritional values of $\mathrm{N}$. sativa meal were documented in the study of Attia et al. [8,9] and El-Deek et al. [10]. $N$. sativa Linn. seeds, its oil, extracts, and some of its active principles, particularly thymoquinone and alpha-hederin, possess remarkable in vitro and in vivo pharmacological activities against a large variety of diseases and found to be relatively safe $[11,12]$.

The aim of this study was to investigate the prophylactic, and immune-stimulant influence of $N$. sativa Linn. in broilers under biological stress (Escherichia coli $\mathrm{O}_{157}: \mathrm{H}_{7} 1.5 \times 10^{8}$ at the $14^{\text {th }}$ day old).

\section{Materials and Methods}

\section{Ethical approval}

All applicable international, national, and/or institutional guidelines for the care and use of birds 
were followed. Staff managed and treated birds as sentient and regarded their proper care and use with minimization of discomfort, distress, and pain. Birds' numbers were minimized to obtain scientifically valid results and to minimize the great suffering of birds. The experiment was not repeated unnecessarily. Birds were housed, feed, and handled in accordance to their needs (behavioral and biological).

\section{Experimental design}

A total of 250 one-day-old chicks (ross) were purchased and housed on battery system. The chicks were divided into five groups; each group consisted of 50 chicks (five replicates of ten birds). The birds were brooded at $33^{\circ} \mathrm{C}$ with a gradual decline by $3^{\circ} \mathrm{C}$ weekly until $25^{\circ} \mathrm{C}$ by the end of $3^{\text {rd }}$ week. The room was supported with natural ventilation means. Artificial light was supplied for at least $18 \mathrm{~h}$ a day. Birds were given ad libitum access to water, as well as a standard corn-soybean basal diet was supplied to meet broiler's dietary requirements as tabulated in Table-1 according to NRC [13].

All birds were vaccinated in drinking water with infectious bronchitis vaccine (live attenuated virus of IB-H120 $\geq 10^{3.5} \mathrm{EID}_{50} /$ dose) at the $7^{\text {th }}$ day of age, infectious bursal disease vaccine (live attenuated virus of $\mathrm{VMG} 91 \geq 10^{3.0} \mathrm{TCID}_{50}$ ) at the $14^{\text {th }}$ and $21^{\text {st }}$ days of age, and Newcastle disease virus vaccine (live lentogenic ND virus of Lasota $\geq 10^{6.0} \mathrm{EID}_{50}$ ) at the $18^{\text {th }}$ and $28^{\text {th }}$ day. The experiment was designed to last for about 5 weeks (38 days). Mortalities were noticed and recorded daily. Indoor temperature and relative humidity were monitored and recorded daily during the experiment.

\section{N. sativa Linn.}

$N$. sativa Linn. crushed seeds were purchased from authenticated market shop, grinded, and added to the ration from the $1^{\text {st }}$ day of age by rates of $1.4 \%$

Table-1: Feed ingredient and nutrient composition of basal ration at different growth stages of experimental birds.

\begin{tabular}{lcc}
\hline Components & $\begin{array}{c}\text { Starter ration } \\
\mathbf{1 : 1 0} \text { days (\%) }\end{array}$ & $\begin{array}{c}\text { Grower ration } \\
\mathbf{1 1 : 3 8} \text { days (\%) }\end{array}$ \\
\hline Food ingredient & & \\
Yellow corn & 54 & 55 \\
Soybean meal & 22 & 16 \\
Corn gluten & 10 & 15 \\
Lime & 0.50 & 0.50 \\
Dicalcium & 1.0 & 1.0 \\
phosphate & & \\
Sodium chloride & 0.5 & 0.5 \\
DL. Methionine & 2.0 & 1.0 \\
L. Iysine & 1.50 & 1.50 \\
Soybean oil & 3.5 & 4.5 \\
Vitamin premix & 2.5 & 2.5 \\
Mineral premix & 2.5 & 2.5 \\
Nutrient content & & \\
Energy & $2990 \mathrm{Kcal} / \mathrm{kg}$ & $3000 \mathrm{Kcal} / \mathrm{kg}$ \\
Protein & $23 \%$ & $22.5 \%$ \\
Fat & $5.60 \%$ & $2.84 \%$ \\
Row fiber & $3.80 \%$ & $3.39 \%$ \\
\hline
\end{tabular}

(1.4 g/100 g ration) for Group 1 (G1), $2.8 \%(2.8 \mathrm{~g} / 100 \mathrm{~g}$ ration) for Group 2 (G2), 4.2\% (4.2 g/100 g ration) for Group 3 (G3), and 5.6\% (5.6 g/100 g ration) for Group 4 (G4). The fifth group was kept as control group.

\section{E. coli challenge}

Four of the five groups (G1, G2, G3, and G4) were challenged with E. coli $\mathrm{O}_{157}: \mathrm{H}_{7} 1.5 \times 10^{8}$ at the $14^{\text {th }}$ day of age in drinking water [14].

\section{Performance indices}

Average live body weight (LBW) was estimated by weighting representative samples of birds on a weekly intervals (a total of 150 birds were weighted weekly; about 30 birds per group, the birds were chosen randomly and representative for each group), as well as the weekly feed intake, and the amount consumed by each bird per grams was calculated based on the birds capacity. Based on the estimated LBW and the calculated feed intake, a number of indices were calculated as indicators for broiler performance including: Weekly body weight gain (BWG) calculated by subtracting X1 LBW from X2 LBW and expressed as grams/week, weekly feed conversion ratio (FCR) calculated by dividing weekly feed intake per grams to weekly BWG per gram, and weekly performance index (PI) calculated by dividing average weekly LBW by kg to weekly FCR [15].

\section{Sampling}

A total of 1050 samples (150 serum, 150 swab, and 750 organ samples including thymus, spleen, bursa, heart, and liver) were collected during the study period, and sampling was carried out on a weekly basis (six birds/each group/week). Blood samples were collected from the five groups and kept for overnight at $4^{\circ} \mathrm{C}$, centrifuged at $3000 \mathrm{rpm}$ for $20 \mathrm{~min}$ for serum separation. A clear non-hemolyzed sera were divided into 3 equal parts in Eppendorf tubes, stored at $-20^{\circ} \mathrm{C}$ until used for biochemical analysis [16]. Birds (about 30 birds/week) were slaughtered after blood sampling; thymus, spleen, bursa, heart, and liver were removed, weighed, and expressed as $\mathrm{g} / \mathrm{kg} \mathrm{BW}$, and then, all organs were washed with $5 \%$ phosphate buffered saline (PBS) and kept on 10\% buffered formalin for histopathological examination. Swab samples were collected from birds' intestine on $9 \mathrm{~mL}$ phosphate buffer saline, preserved in the icebox, and transferred to the laboratory for bacteriological assessment.

\section{Biochemical analysis}

Serum samples were examined for the biochemical changes in some parameters as total protein, albumin, globulin, alanine aminotransferase (ALT), aspartate aminotransferase (AST), urea, and creatinine calorimetrically [17]. Serum immunoglobulin G (IgG), IgM, and IgA concentrations were measured using immunoturbidimetric assay [18].

\section{Bacteriological examination}

All swabs were prepared according to APHA [19]. On arrival to the laboratory, 10 -fold serial dilution 
was carried out up to $10^{-6}$ to cover the expected range of samples contamination, which could be easily counted.

Bacterial counts (total bacterial count $[\mathrm{TBC}]$ and total Enterobacteriaceae count [TEC]) were applied using drop plate technique [20]. TBC was performed using standard plate count agar at $37^{\circ} \mathrm{C}$ for $24-48 \mathrm{~h}$. On the other hand, TEC was conducted using eosin methylene blue agar at $37^{\circ} \mathrm{C}$ for $24-48 \mathrm{~h}$. Plates showed 30-300 CFU per plate were counted [21].

\section{Histopathological examination}

Thymus, spleen, bursa, heart, and liver were washed with $5 \%$ PBS, preserved in $10 \%$ buffered formalin saline until further processing. Specimens were cut into $5 \mathrm{~mm}$ thickness sections and put into tissue cassettes. They were dehydrated by transferring through a series of alcohols with increasing concentrations, cleared in xylol, and embedded in paraffin. The obtained sections were stained with hematoxylin and eosin [22]. Histological sections were examined using Zeiss Axioplan microscope (Carl Zeiss MicroImaging, Thornwood, NY) magnification 40×.

\section{Statistical analysis}

Statistical analysis was carried out using statistical package for social sciences [23], statistical analysis system [24], and Levesque [25]. Means and standard errors were calculated using Windows Excel, and the obtained data were analyzed statistically using multifactorial analysis of variance (ANOVA) with the general linear model for all treated groups, age, and their interactions. Data were subjected to two-way ANOVA as variables were fitted as independent factors, the following equation was used:

$\mathrm{Y}_{\mathrm{ijkl}}=\mu+\mathrm{G}_{\mathrm{i}}+\mathrm{W}_{\mathrm{k}}+\mathrm{GW}_{\mathrm{ik}}+\mathrm{e}_{\mathrm{ijk}}$

Where $Y_{i j k l}$ is the examined variable, $\mu$ is the overall mean of the model, $\mathrm{B}_{\mathrm{i}}$ is the effect of group, $\mathrm{W}_{\mathrm{k}}$ is the effect of age in weeks, $\mathrm{GW}_{\mathrm{ik}}$ is the interaction of group by age of bird, and $\mathrm{e}_{\mathrm{ijkl}}$ is the error. Bivariate correlation coefficient was calculated to compare the influence of bacterial counts, immune organs' weight, and IGs concentration on each other.

\section{Results}

In Table-2, body weight showed significant increase $(\mathrm{p}<0.01)$ with the increase in $N$. sativa Linn. supplementation, especially in broilers fed on $4.2 \%$ and $5.6 \%$ N. sativa Linn. Weight gain and PI revealed a superiority in birds fed on $5.6 \%$ with significant differences $(p<0.01)$ compared to the other treated groups and controls. Meanwhile, FCR revealed non-significant differences between all supplemented groups compared to the control.

In Table-3, proteinogram revealed a highly significant increase $(\mathrm{p}<0.01)$ in total protein and albumin and a highly significant decrease $(p<0.01)$ in globulin in broilers fed $5.6 \% N$. sativa Linn. Liver enzymes (ALT, AST) and creatinine also showed a highly significant increase $(\mathrm{p}<0.01)$ in broilers fed $5.6 \% N$. sativa Linn. On the contrary, urea revealed a significant increase in all treated groups from the normal control group with high significant differences $(\mathrm{p}<0.01)$.

IgG and IgA revealed a highly significant improvement in broilers fed $4.2 \%$ and $5.6 \% \mathrm{~N}$. sativa Linn. with significant differences $(p<0.01)$ from the other groups (Table-4), while IgM revealed non-significant differences among different groups. On the other hand, IGs revealed a significant $(\mathrm{p}<0.01)$ strong positive correlations between each other, and the increases in $\operatorname{IgG}$ and $\operatorname{IgA}$ are accompanied with an increase in IgM (Table-5).

In Table-4, TBC and TEC showed highly significant decline $(\mathrm{p}<0.01)$ in broilers fed $5.6 \% \mathrm{~N}$. sativa Linn. compared to the other groups. TBC in Table-5 revealed a highly significant weak positive correlations $(\mathrm{p}<0.01)$ with all of thymus, $\operatorname{IgG}, \operatorname{IgA}$, and IgM concentrations. On the other hand, TEC revealed significant intermediate negative correlations $(\mathrm{p}<0.01)$ with $\operatorname{IgG}$ and IgM. A significant weak negative correlation was detected between TEC and IgA. Furthermore, a highly significant weak positive correlations $(p<0.01)$ was detected between TEC and bursa. In Table-6, immune organs (thymus, spleen, and bursa) revealed a synchronized highly significant improvement $(\mathrm{p}<0.01)$ in broilers fed 5.6\% N. sativa Linn. compared to the other groups.

Histopathological section of liver from broilers fed on $N$. sativa Linn. $1.4 \%$ and $2.8 \%$ as shown in Figure- $1 \mathrm{~b}$ and $\mathrm{c}$ revealed severe perihepatitis, severe leukocytic infiltrations, and hydropic degeneration in majority of hepatocytes compared to normal microscopic picture of liver in Figure-1a. Heart in broilers

Table-2: Performance traits (mean \pm SE) in different experimental groups supplemented with $N$. sativa Linn. in face of E. coli challenge.

\begin{tabular}{lcccc}
\hline $\boldsymbol{N}$ sativa Linn. & Body weight $(\mathbf{g})$ & Weight gain $(\mathbf{g})$ & FCR $(\%)$ & Performance index \\
\hline $1.4 \%$ & $971.767^{\mathrm{c}} \pm 4.070$ & $422.033^{\mathrm{a}} \pm 6.554$ & $1.439^{\mathrm{b}} \pm 0.028$ & $6.835^{\mathrm{b}} \pm 0.181$ \\
$2.8 \%$ & $1055.230^{\mathrm{b}} \pm 19.083$ & $372.893^{\mathrm{ab}} \pm 4.131$ & $1.558^{\mathrm{b}} \pm 0.013$ & $6.655^{\mathrm{b}} \pm 0.686$ \\
$4.2 \%$ & $1083.467^{\mathrm{b}} \pm 20.383$ & $388.500^{\mathrm{ab}} \pm 9.152$ & $1.526^{\mathrm{b}} \pm 0.121$ & $7.082^{\mathrm{a}} \pm 0.336$ \\
$5.6 \%$ & $1118.363^{\mathrm{a}} \pm 29.522$ & $418.210^{\mathrm{a}} \pm 6.439$ & $1.306^{\mathrm{b}} \pm 0.186$ & $7.834^{\mathrm{a}} \pm 0.254$ \\
Control & $963.133^{\mathrm{c}} \pm 2.316$ & $330.900^{\mathrm{b}} \pm 5.600$ & $2.048^{\mathrm{a}} \pm 0.115$ & $5.443^{\mathrm{c}} \pm 0.981$ \\
p value & 0.001 & 0.010 & 0.001 & 0.001 \\
\hline
\end{tabular}

Means carrying different superscripts in the same column are significantly different at $p \leq 0.05$ or highly significantly different at $p<0.01$. Means carrying the same superscripts in the same column are non-significantly different at $p>0.05$. $N$. sativa $=$ Nigella sativa, $E$. coli $=$ Escherichia coli, $\mathrm{FCR}=$ Feed conversion ratio 
Table-3: Biochemical parameters (mean \pm SE) in different experimental groups supplemented with $N$. sativa Linn. in the face of $E$. coli challenge.

\begin{tabular}{lccccccc}
\hline $\begin{array}{l}\boldsymbol{N} \text {. sativa } \\
\text { Linn. }\end{array}$ & $\begin{array}{c}\text { Total } \\
\text { protein }(\mathbf{g} / \mathbf{d l})\end{array}$ & $\begin{array}{c}\text { Albumin } \\
\mathbf{( g / d l )}\end{array}$ & $\begin{array}{c}\text { Globulin } \\
(\mathbf{g} / \mathbf{d l})\end{array}$ & $\begin{array}{c}\text { ALT } \\
(\mathbf{I U} / \mathbf{L})\end{array}$ & $\begin{array}{c}\text { AST } \\
(\mathbf{I U} / \mathbf{L})\end{array}$ & $\begin{array}{c}\text { Urea } \\
(\mathbf{m g} / \mathbf{d l})\end{array}$ & $\begin{array}{c}\text { Creatinine } \\
(\mathbf{m g} / \mathbf{d l})\end{array}$ \\
\hline $1.4 \%$ & $3.57^{\mathrm{d}} \pm 0.017$ & $1.87^{\mathrm{d}} \pm 0.002$ & $1.69^{\mathrm{c}} \pm 0.025$ & $27.18^{\mathrm{b}} \pm 0.051$ & $36.18^{\mathrm{b}} \pm 0.098$ & $79.26^{\mathrm{b}} \pm 0.132$ & $0.56^{\mathrm{d}} \pm 0.012$ \\
$2.8 \%$ & $4.39^{\mathrm{b}} \pm 0.008$ & $3.17^{\mathrm{b}} \pm 0.008$ & $1.22^{\mathrm{d}} \pm 0.014$ & $26.91^{\mathrm{c}} \pm 0.020$ & $36.18^{\mathrm{b}} \pm 0.154$ & $75.12^{\mathrm{c}} \pm 0.054$ & $0.74^{\mathrm{b}} \pm 0.003$ \\
$4.2 \%$ & $4.39^{\mathrm{b}} \pm 0.014$ & $2.37^{\mathrm{c}} \pm 0.007$ & $2.02^{\mathrm{a}} \pm 0.013$ & $25.71^{\mathrm{d}} \pm 0.051$ & $34.88^{\mathrm{c}} \pm 0.103$ & $73.62^{\mathrm{d}} \pm 0.688$ & $0.49^{\mathrm{e}} \pm 0.006$ \\
$5.6 \%$ & $4.99^{\mathrm{a}} \pm 0.012$ & $3.87^{\mathrm{a}} \pm 0.012$ & $1.12^{\mathrm{e}} \pm 0.030$ & $27.41^{\mathrm{a}} \pm 0.081$ & $36.68^{\mathrm{a}} \pm 0.075$ & $75.72^{\mathrm{c}} \pm 0.233$ & $0.84^{\mathrm{a}} \pm 0.018$ \\
Control & $3.59^{\mathrm{c}} \pm 0.007$ & $1.87^{\mathrm{d}} \pm 0.027$ & $1.72^{\mathrm{b}} \pm 0.018$ & $27.21^{\mathrm{b}} \pm 0.104$ & $36.18^{\mathrm{b}} \pm 0.132$ & $81.62^{\mathrm{a}} \pm 0.054$ & $0.59^{\mathrm{c}} \pm 0.025$ \\
p value & 0.001 & 0.001 & 0.001 & 0.001 & 0.001 & 0.001 & 0.001 \\
\hline
\end{tabular}

Means carrying different superscripts in the same column are significantly different at $p \leq 0.05$ or highly significantly different at $p<0.01$. Means carrying the same superscripts in the same column are non-significantly different at $p>0.05$. ALT=Alanine aminotransferase, AST=Aspartate aminotransferase, $N$. sativa=Nigella sativa, $E$. coli=Escherichia coli, $\mathrm{SE}=$ Standard error

Table-4: Immunoglobulin levels and logarithmic bacterial count (mean $\pm S E$ ) in different experimental groups supplemented with $N$. sativa Linn. in the face of $E$. coli challenge.

\begin{tabular}{lccccc}
\hline N. sativa Linn. & \multicolumn{3}{c}{ Immunoglobulin } & \multicolumn{2}{c}{ Log bacterial count } \\
\cline { 2 - 6 } & IgG $\mathbf{( m g / m I )}$ & IgA $\mathbf{( m g / m I )}$ & IgM $\mathbf{( m g / m I )}$ & TBC (CFU/mI) & TEC (CFU/mI) \\
\hline $1.4 \%$ & $1.359^{\mathrm{a}} \pm 0.006$ & $0.153^{\mathrm{a}} \pm 0.003$ & $0.204^{\mathrm{a}} \pm 0.006$ & $3.664^{\mathrm{d}} \pm 0.005$ & $3.990^{\mathrm{a}} \pm 0.014$ \\
$2.8 \%$ & $1.195^{\mathrm{b}} \pm 0.026$ & $0.144^{\mathrm{b}} \pm 0.085$ & $0.200^{\mathrm{a}} \pm 0.013$ & $3.673^{\mathrm{d}} \pm 0.006$ & $3.760^{\mathrm{b}} \pm 0.063$ \\
$4.2 \%$ & $1.340^{\mathrm{a}} \pm 0.027$ & $0.155^{\mathrm{a}} \pm 0.007$ & $0.206^{\mathrm{a}} \pm 0.014$ & $3.812^{\mathrm{b}} \pm 0.011$ & $3.113^{\mathrm{d}} \pm 0.015$ \\
$5.6 \%$ & $1.194^{\mathrm{b}} \pm 0.002$ & $0.143^{\mathrm{b}} \pm 0.008$ & $0.199^{\mathrm{a}} \pm 0.006$ & $3.769^{\mathrm{c}} \pm 0.006$ & $2.299^{\mathrm{e}} \pm 0.018$ \\
Control & $1.318^{\mathrm{a}} \pm 0.009$ & $0.153^{\mathrm{a}} \pm 0.002$ & $0.204^{\mathrm{a}} \pm 0.004$ & $5.747^{\mathrm{a}} \pm 0.002$ & $3.502^{\mathrm{c}} \pm 0.009$ \\
p value & 0.001 & 0.001 & 0.662 & 0.001 & 0.001
\end{tabular}

Means carrying different superscripts in the same column are significantly different at $p \leq 0.05$ or highly significantly different at $p<0.01$. Means carrying the same superscripts in the same column are non-significantly different at $\mathrm{p}<0.05$. N. sativa $=$ Nigella sativa, $E$. coli $=$ Escherichia coli, $\mathrm{SE}=$ Standard error, $\mathrm{TBC}=$ Total bacterial count, $\mathrm{TEC}=\mathrm{Total}$ Enterobacteriaceae count, Ig=Immunoglobulin

Table-5: Correlation coefficient between immune organs' weight, Ig levels with logarithmic TBC (above diagonal), and logarithmic TEC (below diagonal).

\begin{tabular}{|c|c|c|c|c|c|c|c|}
\hline $\mathbf{r}$ & $\log$ TBC & Thymus & Spleen & Bursa & IgG & IgA & IgM \\
\hline Log TEC & 1 & $0.331 * *$ & $0.177 *$ & 0.010 & $0.266 * *$ & $0.363 * *$ & $0.257 * *$ \\
\hline Thymus & 0.092 & 1 & $0.853 * *$ & $0.829 * *$ & 0.170* & $0.645^{* *}$ & 0.148 \\
\hline Spleen & 0.042 & $0.853 * *$ & 1 & $0.831 * *$ & $0.274 * *$ & $0.721 * *$ & $0.269 * *$ \\
\hline Bursa & $0.227 * *$ & $0.829 * *$ & $0.831 * *$ & 1 & 0.033 & $0.527 * *$ & 0.013 \\
\hline IgG & $-0.474 * *$ & $0.170 *$ & $0.274 * *$ & 0.033 & 1 & $0.801 * *$ & $0.990 * *$ \\
\hline IgA & $-0.200 *$ & $0.645^{* *}$ & $0.721 * *$ & $0.527 * *$ & $0.801 * *$ & 1 & $0.795^{* *}$ \\
\hline IgM & $-0.454 * *$ & 0.148 & $0.269 * *$ & 0.013 & $0.990 * *$ & $0.795 * *$ & 1 \\
\hline
\end{tabular}

**Correlation is highly significant $(p<0.01)$. $*$ Correlation is significant $(p<0.05)$. ${ }^{\text {Ns Correlation is }}$ non-significant $(p>0.05)$. TBC $=$ Total bacterial count, TEC = Total Enterobacteriaceae count, Ig = Immunoglobulin

Table-6: Immune organs' weight (mean \pm SE) in different experimental groups supplemented with $N$. sativa Linn. in the face of $E$. coli challenge.

\begin{tabular}{lccc}
\hline $\boldsymbol{N}$ s sativa Linn & Thymus $(\mathbf{g} / \mathbf{k g})$ & Spleen $\mathbf{( g / k g )}$ & Bursa $(\mathbf{g} / \mathbf{k g})$ \\
\hline $1.4 \%$ & $2.494^{\mathrm{c}} \pm 0.008$ & $2.495^{\mathrm{c}} \pm 0.045$ & $2.546^{\mathrm{a}} \pm 0.036$ \\
$2.8 \%$ & $2.415^{\mathrm{d}} \pm 0.105$ & $2.586^{\mathrm{b}} \pm 0.021$ & $1.793^{\mathrm{d}} \pm 0.081$ \\
$4.2 \%$ & $2.900^{\mathrm{a}} \pm 0.027$ & $2.460^{\mathrm{c}} \pm 0.101$ & $2.014^{\mathrm{c}} \pm 0.010$ \\
$5.6 \%$ & $2.743^{\mathrm{b}} \pm 0.018$ & $2.760^{\mathrm{a}} \pm 0.054$ & $2.334^{\mathrm{b}} \pm 0.011$ \\
Control & $2.791^{\mathrm{b}} \pm 0.063$ & $2.211^{\mathrm{d}} \pm 0.081$ & $1.674^{\mathrm{e}} \pm 0.041$ \\
p value & 0.001 & 0.001 & 0.001 \\
\hline
\end{tabular}

Means carrying different superscripts in the same column are significantly different at $p \leq 0.05$ or highly significantly different at $p<0.01$. Means carrying the same superscripts in the same column are non-significantly different at $P>0.05$. N. sativa=Nigella sativa, E. coli=Escherichia coli, $\mathrm{SE}=$ Standard error

fed on $1.4 \%$ and $2.8 \%$ N. sativa Linn. (Figure- $2 \mathrm{~b}$ and c) showed severe pericarditis with partial extension to myocardium resulting in myocarditis compared to normal histological picture of heart (Figure-2a). Some of the myocardial cells showed vacuolated cytoplasm. Meanwhile, bursa, thymus, and spleen of broilers fed on $1.4 \%$ and $2.8 \%$ N. sativa Linn. (Figures-3b and c, $4 \mathrm{~b}$ and c, $5 \mathrm{~b}$ and c) revealed severe lymphoid depletion compared to normal histological pictures (Figures-3a, $4 \mathrm{a}$ and $5 \mathrm{a}$ ).

The examination of liver from broilers fed on N. sativa Linn. 4.2\% in Figure-1d showed a moderate 

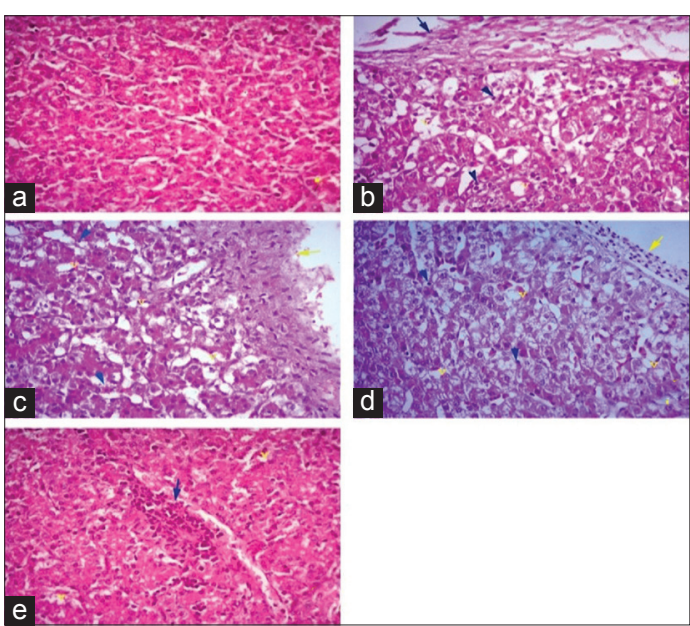

Figure-1: Histopathological examination of the liver in different broilers groups fed on different concentrations of Nigella sativa Linn. (a) Liver of control broilers. (b) Liver of broilers fed $N$. sativa Linn. $1.4 \%$. (c) Liver of broilers fed $N$. sativa Linn. $2.8 \%$. (d) Liver of broilers fed $N$. sativa Linn. $4.2 \%$. (e) Liver of broilers fed N. sativa Linn. $5.6 \%$ ( $H$ and $E, 40 \times$ ).
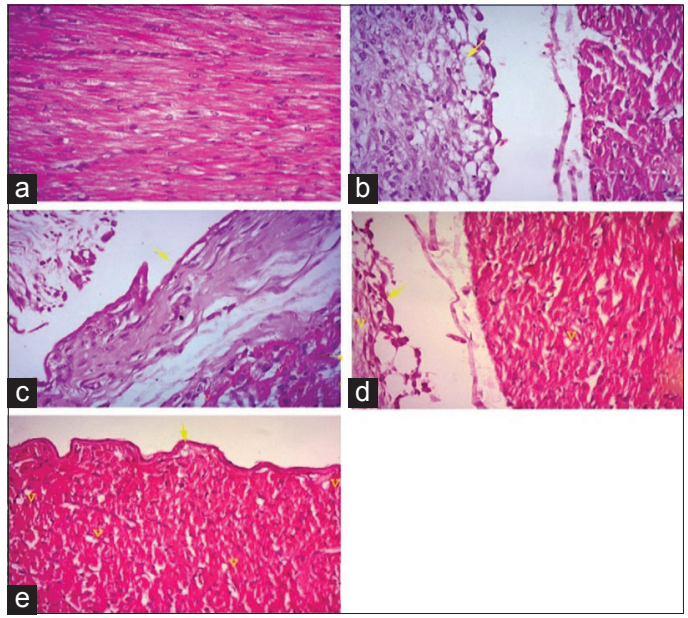

Figure-2: Histopathological examination of the heart in different broilers groups fed on different concentrations of Nigella sativa Linn. (a) Heart of control broilers. (b) Heart of broilers fed $N$. sativa Linn. $1.4 \%$. (c) Heart of broilers fed $N$. sativa Linn. $2.8 \%$. (d) Heart of broilers fed $N$. sativa Linn. $4.2 \%$. (e) Heart of broilers fed N. sativa Linn. $5.6 \%$ ( $\mathrm{H}$ and $\mathrm{E}, 40 \times$ ).

degree of perihepatitis with vacuolated cytoplasm, in the majority of hepatocytes, the vacuoles surrounded with irregular boundaries indicating hydropic degeneration with leukocytic infiltration compared to normal microscopic picture of liver (Figure-1a). Heart in broilers fed on N. sativa Linn. 4.2\% (Figure-2d) revealed moderate pericarditis, and some of myocardial cells showed vacuolated cytoplasm compared to normal histological picture in Figure-2a. Spleen, bursa, and thymus of broilers fed on $N$. sativa Linn. $4.2 \%$ (Figures-3d, 4d and 5d) showed mild lymphoid depletion with severe vacuolation compared to normal microscopic pictures (Figures-3a, 4a and 5a).

Liver of broilers fed on $N$. sativa Linn. 5.6\% in Figure-1e showed pronounced improvement of
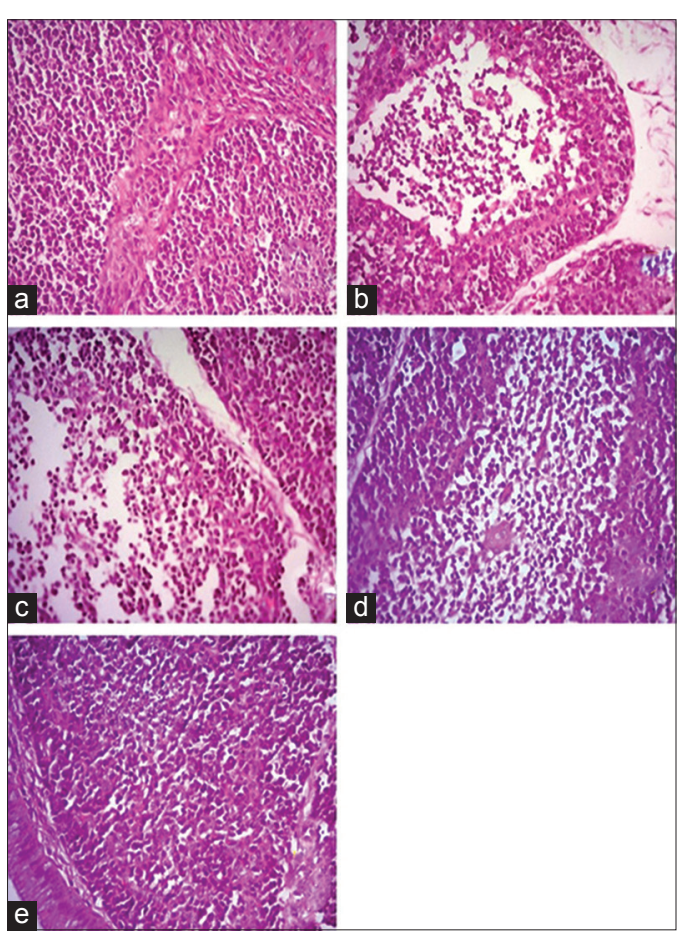

Figure-3: Histopathological examination of the Bursa in different broilers groups fed on different concentrations of Nigella sativa Linn. (a) Bursa of control broilers. (b) Bursa of broilers fed $N$. sativa Linn. $1.4 \%$. (c) Bursa of broilers fed $N$. sativa Linn. $2.8 \%$. (d) Bursa of broilers fed $N$. sativa Linn. $4.2 \%$. (e) Bursa of broilers fed $N$. sativa Linn. $5.6 \%$ ( $H$ and $E, 40 \times$ ).
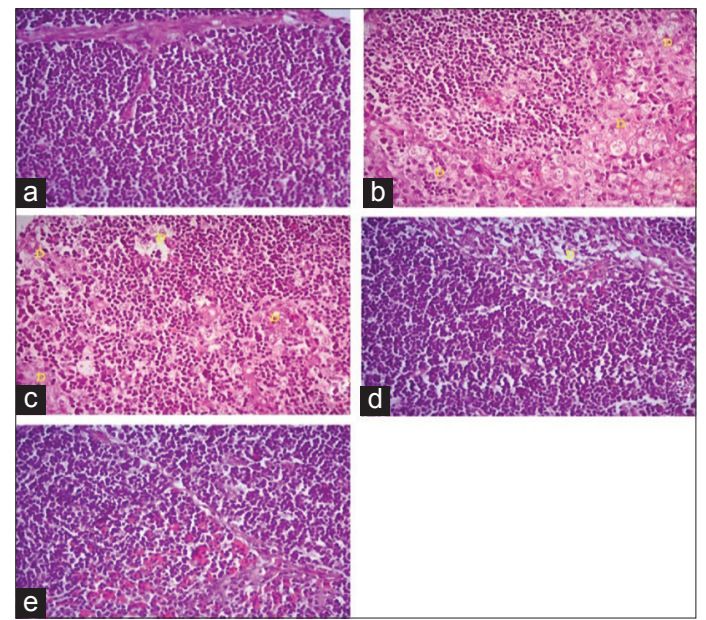

Figure-4: Histopathological examination of the thymus in different broilers groups fed on different concentrations of Nigella sativa Linn. (a) Thymus of control broilers. (b) Thymus of broilers fed $N$. sativa Linn. $1.4 \%$. (c) Thymus of broilers fed $N$. sativa Linn. $2.8 \%$. (D) Thymus of broilers fed $N$. sativa Linn. $4.2 \%$. (e) Thymus of broilers fed $N$. sativa Linn. $5.6 \%(\mathrm{H}$ and $\mathrm{E}, 40 \times)$.

hepatocytes with no proliferation of fibroblasts, and only mild vacuolar degeneration of hepatocytes and mild leukocytic infiltration were observed compared to normal microscopic picture of liver (Figure-1a). Heart of broilers fed on $5.6 \%$ N. sativa Linn (Figure-2e) showed mild pericarditis with a mild degree of hydropic degeneration in some myocardial cells compared to normal microscopic appearance (Figure-2a). 


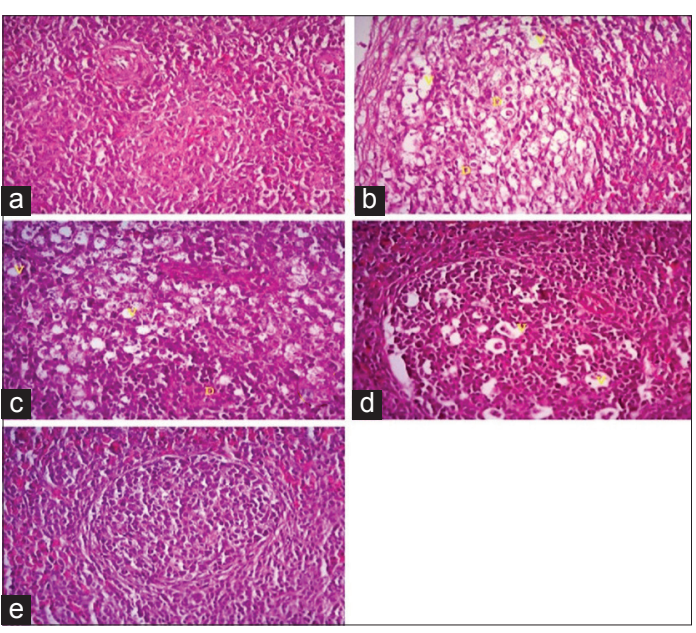

Figure-5: Histopathological examination of the spleen in different broilers groups fed on different concentrations of Nigella sativa Linn. (a) Spleen of control broilers. (b) Spleen of broilers fed $N$. sativa Linn. $1.4 \%$. (c) Spleen of broilers fed $N$. sativa Linn. $2.8 \%$. (d) Spleen of broilers fed N. sativa Linn. $4.2 \%$. (e) Spleen of broilers fed $N$. sativa Linn. $5.6 \%$ ( $H$ and $E, 40 \times)$.

Bursa, thymus, and spleen of broilers fed on N. sativa Linn. 5.6\% (Figures-3e, 4e and 5e) showed lymphoid hyperplasia compared to normal histological picture in Figures-3a, 4a and 5a.

\section{Discussion}

$N$. sativa Linn. was reported as growth promoter and significant source of essential nutritive substances according to the study of Attia et al. [1,8,9], El-Deek et al. [10], and Benhelima et al. [26], including about $26.7 \%$ protein, $33.2 \%$ carbohydrate, and $38.7 \%$ fat. These nutrients contributed a great enhancement in performance traits, especially body weight and weight gain, after supplementation in a rate of 1 and $1.5 \%$ for 42 days as reported by EL-Shoukary et al. [27], these results were in favor of our results which concluded that $N$. sativa Linn. supplementation at rate of $4.2 \%$ and $5.6 \%$ was successfully able to enhance the performance traits.

Meanwhile, FCR in the current study revealed non-significant differences between all supplemented groups compared to the control. Controversy results were documented by Boka et al. [28], who found a great enhancement in FCR in broilers supplemented with $0,1,2$, and $3 \% N$. sativa Linn. seeds, and the best FCR was recorded in broilers fed on $2 \% N$. sativa Linn. Controversy results were documented by Jahan et al. [29], who found that FCR was improved using $1.5 \%$ N. sativa Linn. seeds at the early age of 14 days old.

Others indicated that $N$. sativa Linn. supplementation at rates of $0.25 \%, 0.75 \%, 1 \%$, and $2 \%$ had undesirable effects on performance and carcass quality as recorded by Majeed et al. [30] and Nasir and Grashorn [31], the same conclusions were found in our study, especially, that lower concentrations of $N$. sativa Linn. $(1.4 \%, 2.8 \%)$ were not able to exert these performance enhancement and immune-stimulant effects. Meanwhile, Marian H. Ghaly et al. [32] found that addition of $N$. sativa and their combinations for long periods could not alter liver and kidney histology and physiology and increased liver weight and dressing percentage.

$N$. sativa Linn., in our study, resulted in a significant increase in total protein and albumin and significant decrease in globulin in G4 in agreement with the findings of AL-Beitawi et al. [33], who found that by the addition of $2 \% N$. sativa Linn. seeds in broiler diet resulted in increased total plasma protein. The present study disagreed with the findings of Salam et al. [34], who found that feeding 20,40 , and $60 \mathrm{~g} / \mathrm{kg} N$. sativa Linn. seeds in broilers diet did not significantly affect on physical properties of blood. Azeem et al. [35] showed that supplementation of broilers diet with $N$. sativa Linn. 1 or $3 \%$ strengthened the immunity by preventing liver damage and decreasing serum phospholipids and cholesterol. Furthermore, Hermes et al. [36] found a role of $N$. sativa Linn. in activating the function of the liver without any toxic effect on the liver or kidney; they reported unaltered liver enzyme activity in contrast to our results which is supported with the study of Sogut et al. [37], who showed that the $N$. sativa Linn. decreased the hepatic liver peroxidation and increased the activities of several enzymes such as glutathione-S-transferase, catalase, myeloperoxidase, and adenosine deaminase all of which resulted in decreased oxidative stress on the liver using 3, 5, and 7\% N. sativa Linn.

Our results revealed significant improvement in IgG and IgA of birds fed on N. sativa Linn. $4.2 \%$ and $5.6 \%$ and non-significant changes in IgM in all treated groups and control. A highly significant strong positive correlations was detected in IGs pattern. The same obtained with Al-Mufarrej [38], who investigated the immune-responsiveness and performance of broiler chickens fed $N$. sativa Linn. powder, his study showed that dietary supplement of $N$. sativa Linn. seeds at the level of $1 \%$ or $1.4 \%$ would enhance immune responsiveness in broiler chickens.

The synchronized highly significant improvement of thymus, spleen, and bursa in birds fed on $N$. sativa Linn. $5.6 \%$ was supported by the results showed by Umar et al. [39], who reported an enhanced immune responsiveness and reduced pathogenicity of Avian Influenza H9N2 in birds supplemented with N. sativa Linn. $3 \%$.

$N$. sativa Linn. was also able to increase the broilers resistance with effective limitation for the propagation of Enterobacteriaceae as reported by Erener et al. [40], these finding supported our finding for the significant decline of both total and Enterobacteriaceae counts from the broilers' intestine. The present study also revealed a significant increase in IG concentration (IgG and $\operatorname{IgA}$ ) with great enhancement of the histopathological picture of immune organs (thymus, 
bursa, and spleen). These findings were supported by those declared by Altunoglu et al. [41] and Shewita and Taha [42]. From the previous results concerning IGs, immune organs, and bacterial count, we could prove the protective and immune-stimulation effect of $N$. sativa Linn.

E. coli infection in birds contributed colibacillosis and subsequent morbidity and mortality, with heavy economic losses in poultry industry. E. coli infection in broilers usually opened a gate for secondary infection with other microorganisms through lowering the bird's resistance causing severe illness and deaths in birds. Colibacillosis usually characterized by septicemia in acute stage resulting in death and pericarditis, airsacculitis, and perihepatitis in the subacute stage [43]. E. coli infection was clearly known to contribute marked gross and microscopic bursal lesions causing bursal atrophy that subsequently resulted in transient humeral immunosuppression [44].

$N$. sativa Linn. has been reported to exert many biological activities as immune-stimulant, respiratory-stimulant, antihypertensive, antidiabetic, analgesic, anti-inflammatory, anti-ulcerogenic, antibacterial, antifungal, anthelmintic, and antitumor actions $[1,45,46]$. $N$. sativa Linn. was found to have an antimicrobial activity on E. coli, Bacillus subtilis, Streptococcus faecalis, Staphylococcus aureus, Pseudomonas aeruginosa, and Candida albicans $[47,48]$.

Our result revealed that $N$. sativa Linn. 1.4\% and $2.8 \%$ showed severe perihepatitis and severe pericarditis with partial extension to myocardium, resulting in myocarditis. Furthermore, bursa, thymus, and spleen revealed severe lymphoid depletion. The histopathological picture of these concentrations improves the inability to perform a protective action against $E$. coli. These lesions were in consistent with the study of Bopp et al. [49], who found that E. coli infection in broilers prevailed at 3-12 weeks, and frequently followed by generalized septicemia, perihepatitis, and pericariditis. Nakamura et al. [50] also mentioned that $E$. coli infection contributed a severe damage in the immune systems of broilers including lymphocyte depletion in both bursa and thymus.

$N$. sativa Linn. was reported to have anti-inflammatory [51], renal-protective [52], hepatoprotective [53], and immune-potentiating [54] properties. $N$. sativa Linn. also had an antibacterial actions against a wide range of microorganisms [55]. Our results revealed that broilers feed on $N$. sativa Linn. $4.2 \%$ showed moderate perihepatitis and moderate pericarditis. Spleen, bursa, and thymus showed mild lymphoid depletion. While feeding on N. sativa Linn., $5.6 \%$ showed pronounced improvement of hepatocytes with no proliferation of fibroblasts, mild pericarditis. Bursa, thymus, and spleen showed lymphoid hyperplasia.

Histopathological examination in our study emphasizes the improvement in the organs' pictures on feeding higher level of $N$. sativa Linn., and this is may be due to its antimicrobial properties, which could decrease the harmful effect after challenge with E. coli. The present findings are in contrast to that of Marian et al. [32], who revealed that the histopathological examination, after feeding on $N$. sativa Linn. oil (at a dosage rate of $2 \mathrm{ml} / \mathrm{kg}$ basal diet) for 6 weeks in 1-day-old broilers, at day 21, and day 42 of broilers age, the liver and kidney sections showed degeneration, he reported that it might be due to the toxic effects of $N$. sativa Linn.

\section{Conclusion}

$N$. sativa Linn. supplementation at the rate of $4.2 \%$ and $5.6 \%$ in broilers can be used efficiently as growth promoters to enhance the performance traits including BWG, FCR, and PI and as an immune-modulatory agent to increase the birds' resistance against many diseases including $E$. coli infection.

\section{Authors' Contributions}

ESS designed the experimental design, prepared, supervised, and assisted in each step during the experiment. RTH assisted in laboratory work and conducted the histopathological examination. AA assisted in laboratory work and in writing of the manuscript. All authors read and approved the final manuscript.

\section{Acknowledgments}

Authors are grateful to Prof. Dr. M.A.A. Sobieh for his great and tremendous directions. This study was funded by the authors. The experimental birds were gratefully raised in the facilities of Faculty of veterinary Medicine, Suez Canal University, Ismailia.

\section{Competing Interests}

The authors declare that they have no competing interests.

\section{References}

1. Attia, Y.A. and Al-Harthi, M.A. (2015) Nigella seed oil as an alternative to antibiotic growth promoters for broiler Chickens. Eur. Poult. Sci., 79: 1-15.

2. Kim, J.D., Nhut, T.M., Hai, T.N. and Ra, C.S. (2011) Effect of dietary essential oils on growth, feed untilization and meat yields of white leg shrimp L. vannamei. Asian Aust. J. Anim. Sci., 24(8): 1136-1141.

3. Hassanpou, H., Zamani-Moghaddam, A.K., Khosravi, M. and Mayahi, M. (2013) Effect of symbiotic on the intestinal morphology and humoral immune response in broiler chickens. Livest. Sci., 153: 116-122.

4. Chen, W., Wang, J.P., Yan, L. and Huang, Y.Q. (2013) Evaluation of probiotics in diets with different nutrient densities on growth performance, blood characteristics, relative organ weight and breast meat characteristics in broilers. $\mathrm{Br}$. Poult. Sci., 54(5): 635-641.

5. Blajman, J.E., Frizzo, L.S., Zbrun, M.V., Astesana, D.M., Fusari, M.L., Soto, L.P., Rosmini, M.R. and Signorini, M.L. (2014) Probiotics and broiler growth performance: A meta-analysis of randomised controlled trials. Br. Poult. Sci., 55(4): 483-494.

6. Wang, X., Farnell, Y.Z., Peebles, E.D., Kiess, A.S., Wamsley, K.G. and Zhai, W. (2016) Effects of prebiotics, probiotics, and their combination on growth performance, 
small intestine morphology, and resident Lactobacillus of male broilers. Poult. Sci. 95(6): 1332-1340.

7. Al-Bukhari, M.I. (1976) In: Al-Bukhari, S., editor. The Collection of Authentic Sayings of Prophet Mohammad (Peace be Upon Him), Division 71 on Medicine. $2^{\text {nd }}$ ed. Hilal Yayinlari, Ankara.

8. Attia, Y.A., Tag El-Din, A.E., Zeweil, H.S. and Arafat, M.A. (2003) Nutritional evaluation of nigella seed meal and the effect of microbial phytase and amino acids supplementations on its feeding value for Japanese Quai. In: Proceedings $9^{\text {th }}$ Conference on Animal Nutrition. Hurghada, Egypt. p201-217.

9. Attia, Y.A., El-Din, A.E.R., Zeweil, H.S., Hussein, A.S. and Arafat, M.A. (2008) The effect of supplementation of enzyme on laying and reproductive performance in Japanese Quail hens fed nigella seed meal. J. Poult. Sci., 45: 110-115.

10. El-Deek, A.A., Hamdy, S.M., Attia, Y.A. and Khalifah, M.M. (2009) Nigella sativa seed oil meal as a source of plant protein in broiler diets. Egypt. Poult. Sci. J., 29: 39-52.

11. Shamsa, M.T., Al-Bayati, M.T.N. and Ibrahim, I. (2013) The effect of garlic and Nigella sativa on some biochemical and production characteristic in broiler chicken. Kufa J. Vet. Med. Sci., 4(1): 75-80.

12. Abbas, T.E.E. and Ahmed, M.E. (2010) Effect of supplementation of Nigella sativa seeds to the broiler chicks diet on the performance and carcass quality. Int. J. Agric. Sci., 2(2): 9-13.

13. National Research Council, NRC. (1994) Nutrient Requirements for Poultry. $9^{\text {th }}$ ed. National Research Council, New York.

14. Kocijancic, D., Felgner, S., Frahm, M., Komoll, R.M., Iljazovic, A., Pawar, V., Rohde, M., Heise, U., Zimmermann, K., Gunzer, F., Hammer, J., Crull, K., Leschner, S. and Weiss, S. (2016) Therapy of solid tumors using probiotic symbioflor-2-restraints and potential. Oncotarget, 7(16): 22605-22622.

15. Soliman, E.S. and Hassan, R.A. (2017) Evaluation of superphosphate and meta-bisulfide efficiency in litter treatment on productive performance and immunity of broilers exposed to ammonia stress. Adv. Anim. Vet. Sci., 5(6): 253-259.

16. Coles, E.H. (1986) Veterinary Clinical Pathology. WB Saunders Company, Philadelphia, London.

17. Young, D.S. (2001) Effect of Drugs on Clinical Laboratory Test. $5^{\text {th }}$ ed. AACC Press, Washington, D.C.

18. Wu, Y.N., Yan, F.F., Hu, J.Y., Chen, H., Tucker, C.M., Green, A.R. and Cheng, H.W. (2017) The effect of chronic ammonia exposure on acute-phase proteins, immunoglobulin, and cytokines in laying hens. Poult. Sci., 96(6): 1524-1530.

19. American Public Health Association, American Water Works Association, Water Environment Federation. (2012) Standard Methods for the Examination of Water and Wastewater. 22 ${ }^{\text {th }}$ ed. American Water Work Association Publications, Washington D.C.

20. Herigstad, B., Hamilton, M. and Heersink, J. (2001) How to optimize the drop plate method for enumerating bacteria. J. Microbiol. Methods, 44(2): 121-129.

21. Cruickshank, R., Duguid, J.P., Marmion, B.P. and Swain, R.H.A. (1980) The Practice of Medical Microbiology. 12 ${ }^{\text {th }}$ ed., Vol. 2. Churchill Livingstone, Edinburgh, New York. p193, 194, 299.

22. Bancroff, J., Stevenes, A. and Turner, D. (1990) Theory and Practice of Histological Techniques. $3^{\text {rd }}$ ed. Clurechill Livingston, Edinburgh, London.

23. SPSS, Inc. (2001) SPSS for Windows: Computer Software. SPSS, Inc., Chicago.

24. SAS Institute, Inc. (2002) SAS Course Notes on Mixed Model Analysis Using SAS System. SAS Institute, Inc., Cary, NC.

25. Levesque, R. (2007) SPSS Programming and Data Management: A Guide for SPSS and SAS ${ }^{\circledR}$ Users. $4^{\text {th }}$ ed.
SPSS Inc., Chicago IL.

26. Benhelima, A., Omar, Z.K., Hemida, H., Benmahdi, T. and Addou, A. (2016) Nephroprotective and diuretic effect of Nigella sativa L. seeds oil on lithiasic Wistar rats. Afr. $J$. Tradit. Complement Altern. Med., 13(6): 204-214.

27. EL-Shoukary, R.D.M., Darwish, M.H.A. and Abdel-Rahman, M.A.M. (2017) Behavioral, performance, carcass traits and hormonal changes of heat stressed broilers feeding black and coriander seeds. J. Adv. Vet. Res., 4(3): 97-101.

28. Boka, J., Mahdavi, A.H., Samie, A.H. and Jahanian, R. (2014). Effect of different levels of black cumin (Nigella sativa L.) on performance, intestinal Escherichia coli colonization and jejunal morphology in laying hens. Anim. Physiol. Anim. Nutr., 98(2): 373-383.

29. Jahan, M.S., Khairunnesa, M., Afrin, S. and Ali, M.S. (2015) Dietary black cumin (Nizella sativa) seed meal on growth and meat yield performance of broilers. SAARC J. Agric., 13(2): 151-160.

30. Majeed, L.H.A., Abdelati, K.A., Al-Bagir, N.M., Alhaidary, A., Mohamed, H.E. and Beynen, A.C. (2010) Performance of broiler chickens fed diets containing low inclusion levels of black cumin seed. J. Anim. Vet. Adv., 9(21): 2725-2728.

31. Nasir, Z. and Grashorn, M.A. (2010) Effect of Echinacea Purpurea and Nigella Sativa supplementation on broiler performance, carcass and meat quality. J. Anim. Feed Sci., 19: $94-104$

32. Marian H. Ghaly, Ashraf A. Elghoneimy, Hussein K. Mohamed and Marwa F. Ali (2017) Biochemical and histopathological effects of dietary supplementation of Nigella sativa and Mentha piperita oils to Broilers. J. Adv. Vet. Res., 7(1): 7-15.

33. Al-Beitawi, N. and El-Ghousein, S.S. (2008) Effect of feeding different levels of Nigella sativa seeds (black cumin) on performance, blood constituents and carcass characteristics of broiler chicks. Int. J. Poult. Sci., 7: 715-721.

34. Salam, S., Sunarti, D. and Isroli, I. (2013) Physiological responses of blood and immune organs of broiler chicken fed dietary black cumin powder (Nigella sativa) during dry seasons. J. Indones. Trop. Anim. Agric., 38(3): 185-191.

35. Azeem, T., Rehmanb, Z.U., Umar, S., Asifa, M., Arifc, M. and Rahmanc, A. (2014) Effect of Nigella sativa on poultry health and production: A review. Sci. Lett., 2(2): 76-82.

36. Hermes, I.H., Attia, F.M., Ibrahim, K.A. and El-Nesr, S.S. (2010) Physiological responses of broiler chickens to different dietary forms and levels of Nigella sativa L., Egyptian during summer season. J. Agric. Vet. Sci., 4(1): 17-33.

37. Sogut, B., Celik, I. and Tuluce, Y. (2008) The effects of diet supplemented with black cumin (Nigella sativa L.) upon immune potential and antioxidant marker enzymes and lipid peroxidation in broiler chicks. J. Anim. Vet. Adv., 7: 1196-1199.

38. Al-Mufarrej, S.I. (2014) Immune-responsiveness and performance of broiler chickens fed black cumin (Nigella Sativa L.) powder. J. Saudi Soc. Agric. Sci., 13(1): 75-80.

39. Umar, S., Rehman, A., Younus, M., Nisa, Q., Ali, A., Shahzad, M., Abdullah-Shah, M.A., Munir, M.T., Aslam, H.B. and Yaqoob, M. (2016) Effects of Nigella sativa on immune responses and pathogenesis of avian influenza (H9N2) virus in turkeys. J. Appl. Poult. Res., 25(1): 95-103.

40. Erener, G., Altop, N., Ocak, H., Aksoy, S. and Ozturk, E. (2010) Influence of black cumin seed (Nigella sativa L) and seed extract on broilers performance and total coliform bacteria count. Asian J. Anim. Vet. Adv., 5: 128-135.

41. Altunoglu, Y.C., Bilen, S., Ulu, F. and Biswas, G. (2017). Immune responses to methanolic extract of black cumin (Nigella sativa) in rainbow trout (Oncorhynchus mykiss). Fish Shellfish Immunol., 67: 103-109.

42. Shewita, R.S. and Taha, A.E. (2011) Effect of dietary supplementation of different levels of black seed (Nigella 
Sativa L.) on growth, performance, immunological, hematological and carcass parameters of broiler chicks. World Acad. Sci. Eng. Technol., 77: 788-794.

43. Shettima, Y.M., El-Yuguda, A.D., Zanna, M.Y., Abubakar, M.B., Hamisu, T.M., Maina, M.M., Andrew, A., Hambali, I.U. and Baba, S.S. (2016) Serological evidence of infectious bronchitis virus among some poultry species in Maiduguri, Nigeria. Alex. J. Vet. Sci., 51(1): 135-139.

44. Hassanin, O., Abdallah, F. and Awad, A. (2014) Effects of florfenicol on the immune responses and the interferon-inducible genes in broiler chickens under the impact of $E$. coli infection. Vet. Res. Commun., 38(1): 51-58.

45. Jasim, W.K., Hassan, M.S. and Keam, G.G. (2016) Study the effect of Nigella sativa on thyroid function and reproductive hormone of female rat. J. Contemp. Med. Sci., 2(6): 67-69.

46. Mehta, B.K. and Gupta, M. (2016) A rapid and pollutionless microwave assisted efficient extraction from seeds of Nigella sativa. Nat. Prod., 12(2): 62-67.

47. Chahal, K.K., Dhaiwal, K., Kumar, A., Kataria, D. and Singla, N. (2017) Chemical composition of Trachyspermum ammi L. and its biological properties: A review. J. Pharmacogn. Phytochem., 6(3): 131-140.

48. Kooti,W.,Hassanzadeh-Noohi,Z., Sharafi-Ahvazi,N.,AsadiSamani, M. and Ashtary-Larky, D. (2016) Phytochemistry, pharmacology, and therapeutic uses of black seed (Nigella sativa). Chin. J. Nat. Med., 14(10): 732-745.

49. Bopp, C.A., Brenner, F.W., Wells, J.G. and Strockbine, N.A. (2005)Escherichia, Shigella and Salmonella.In:Murray,P.R., Baron, E.J., Pfaller, M.A., Tenover, F.C. and Yolken, R.H., editors. Manual of Clinical Microbiology. American Society for Microbiology, Washington, DC.

50. Nakamura, K., Yuasa, N., Abe, H. and Narita, M. (1990) Effect of infectious bursal disease virus on infections produced by Escherichia coli of high and low virulence in chickens. Avian Pathol., 19: 713-721.

51. Mutabagani, A. and El-Mehdy, S.A.M. (1997) A study of the anti-inflammatory activity of Nigella sativa Linn and thymoquinone in rats. Saudi Pharm. J., 5: 110-113.

52. El-Daly, E.S. (1998) Protective effect of cysteine and Vitamin E, Crocus sativus and Nigella sativa extracts on cisplatin induced toxicity in rats. J. Pharm. Belg, 53: 87-95.

53. Daba, M.H. and Abdel-Rehman, M.S. (1998) Hepatoprotective activity of thymoquinone in isolated rat hepatocytes. Toxicol. Lett., 16: 23-29.

54. Swamy, S.W. and Tan, B.K.H. (2000) Cytotoxic and immune-potentiating effect of ethanoic extract of $N$. sativa L. seeds. J. Ethnopharmacol., 70: 1-7.

55. Sokmen, A., Jones, B.M. and Erturk, M. (1999) Antimicrobial activity of extracts from the cell cultures of some Turkish plants. Phytother. Res., 13: 355-357. 